Risk factors for death. Univariate and multivariate analysis

\begin{tabular}{|c|c|c|c|c|}
\hline & $\begin{array}{c}\text { Univariate analysis } \\
\text { HR }(95 \% \mathrm{Cl})\end{array}$ & p-value & $\begin{array}{c}\text { Multivariate analysis } \\
\mathrm{HR}(95 \% \mathrm{Cl})\end{array}$ & $p$-value \\
\hline Age at first symptom & $1.08(1.07-1.09)$ & $<0.001$ & $1.07(1.06-1.09)$ & $<0.001$ \\
\hline Gender (female) & $0.40(0.29-0.54)$ & $<0.001$ & $0.55(0.38-0.78)$ & 0.001 \\
\hline \multicolumn{5}{|l|}{ Disease subset } \\
\hline IcSSc & $0.57(0.45-0.72)$ & $<0.001$ & - & - \\
\hline dcSSc & $2.74(2.14-3.50)$ & $<0.001$ & $2.33(1.74-3.12)$ & $<0.001$ \\
\hline pressc & $0.05(0.00-0.62)$ & 0.020 & - & - \\
\hline Mode of onset & & & & $<0.001$ \\
\hline $\mathrm{RP}$ & $0.44(0.33-0.58)$ & $<0.001$ & 1 (ref.) & - \\
\hline Puffy Hands & $2.18(1.19-4.00)$ & 0.011 & $2.11(1.07-4.16)$ & 0.031 \\
\hline Arthralgia & $0.92(0.53-1.61)$ & 0.779 & $0.76(0.40-1.45)$ & 0.407 \\
\hline Skin sclerosis & $2.23(1.45-3.42)$ & $<0.001$ & $1.43(0.88-2.33)$ & 0.150 \\
\hline ILD & $11.34(4.97-25.85)$ & $<0.001$ & 3.97 (1.58-9.97) & 0.003 \\
\hline $\mathrm{PAH}$ & $31.00(11.21-85.75)$ & $<0.001$ & $13.92(4.79-40.5)$ & $<0.001$ \\
\hline Others & $2.94(1.51-5.75)$ & 0.002 & $1.83(0.85-3.96)$ & 0.123 \\
\hline ILD & $2.60(2.01-3.35)$ & $<0.001$ & $1.90(1.37-2.65)$ & $<0.001$ \\
\hline РAH & $2.60(2.01-3.35)$ & $<0.001$ & $1.64(1.25-2.15)$ & $<0.001$ \\
\hline SRC & $4.08(2.64-6.30)$ & $<0.001$ & $1.94(1.14-3.31)$ & 0.014 \\
\hline Heart involvement & $2.40(1.89-3.05)$ & $<0.001$ & $1.38(1.05-1.80)$ & 0.020 \\
\hline
\end{tabular}

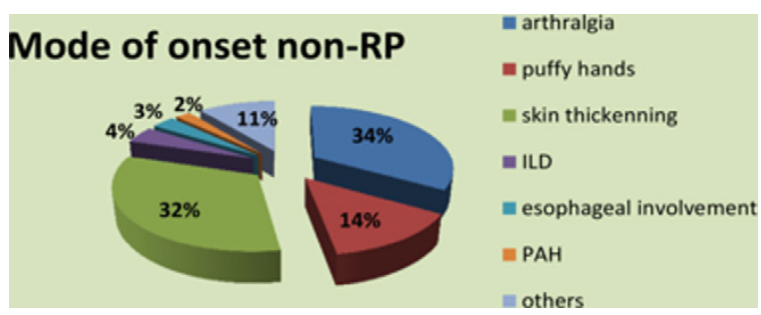

Conclusions: The mode of onset can be considered as independent prognostic factor, and specifically non-RP onset can be considered as a risk factor related to poorer outcome and RP onset and arthralgias can be considered as protector factors.

Disclosure of Interest: None declared

DOI: 10.1136/annrheumdis-2017-eular.1675

\section{FRI0403 INCREASED CRP LEVEL IS INTERRELATED WITH CLINICAL AND SEROLOGICAL PHENOTYPES OF SYSTEMIC SCLERODERMA AND ASSOCIATED WITH CRP RS1205 GENE POLYMORPHISM}

M. Krylov ${ }^{1}$, L. Ananieva ${ }^{1}$, O. Koneva ${ }^{1}$, M. Starovoytova ${ }^{1}$, O. Desinova ${ }^{1}$,

O. Ovsaynnikova ${ }^{1}$, E. Aleksandrova ${ }^{1}$, A. Novikov ${ }^{1}$, I. Guseva ${ }^{1}$, N. Konovalova ${ }^{2}$, D. Varlamov ${ }^{2} \cdot{ }^{1}$ V. A. Nasonova Research Institute of Rheumatology; ${ }^{2}$ All-Russian Research Institute of Agricultural Biotechnology, Moscow, Russian Federation

Background: Recent studies report on increased serum levels of C-reactive protein (CRP) in systemic scleroderma (SSc) pts.

Objectives: The current study was aimed at identifying potential correlations between CRP levels, immunologic SSc phenotypes and CRP rs1205 gene polymorphism in the Russian cohort.

Methods: 92 SSc pts were enrolled in the study. Mean age ( \pm SD) was $49,4 \pm 12,6$ years, mean $( \pm$ SD) SSc duration was $11,1 \pm 9,0$ years, increased CRP levels $>5$ $\mathrm{mg} / \mathrm{l}$ were documented in $43 \%$ pts. CRP levels were analyzed in the following subgroups: with limited (IcSSc) and diffuse (dcSSC) types, with SSc duration $<3$ years $>3$, with or without interstitial lung disease (ILD+) and (ILD-), as well as in subgroups with positive antibody titers to DNA topoisomerase I (ATA+) and antibody to centromeres $(\mathrm{ACA}+)$. CRP concentrations were measured with highly sensitive immunoturbidimertry method. Allele-specific real time PCR was used to study CRP rs1205 gene polymorphism.

Results: Mean CRP $( \pm$ SD) level was significantly higher in dcSSc vs IcSSc $(11,9 \pm 15,5 \mathrm{mg} / \mathrm{l} ; \mathrm{vs} 4,7 \pm 7,4 \mathrm{mg} / \mathrm{l}$, respectively, $p=0,006)$. Pts with disease duration $<3$ years had higher mean CRP levels as compared to pts with SSc duration $>3$ years, although the difference was not significant. In pts with disease duration $>3$ years mean CRP levels were significantly higher among subjects with dcSSc than IcSSc $(11,0 \pm 15,5 \mathrm{mg} / \mathrm{l}$ vs $4,8 \pm 7,7 \mathrm{mg} / \mathrm{l}$, respectively, $p=0,027)$. Mean CRP level was higher in (ATA+) pts than in (ATA-) pts $(11,0 \pm 15,4 \mathrm{mg} / \mathrm{l}$ vs $5,5 \pm 13,7 \mathrm{mg} / \mathrm{l}$, respectively, $p=0,032$ ). No statistical difference in CRP levels was found between $(\mathrm{ILD}+)$ and (ILD-) pts, as well as between (ACA+) and (ACA-) pts.

Carriers of rs 1205 CC genotype had higher CRP levels than carriers of rs1205 $\mathrm{T}$ allele, $p=0,087$ ). In pts with SSc duration $>3$ years and carriers of $\mathrm{rs} 1205$ CC genotype mean CRP level was significantly higher than in T-allele carriers $(12,0 \pm 17,4 \mathrm{mg} / \mathrm{l}$ vs $5,4 \pm 7,4 \mathrm{mg} / \mathrm{l}$, respectively, $p=0,021)$. Similar trends for CRP levels depending on genotypes were established among (ATA+) pts $(16,9 \pm 20,1$ $\mathrm{mg} / \mathrm{l}$ and $7,3 \pm 10,5 \mathrm{mg} / \mathrm{l}$, respectively, $p=0,031$ ).

Conclusions: Increased CRP levels were found almost in 50\% of Russian SSc pts. Higher CRP levels were associated with specific clinical and immunological SSc parameters and CRP rs 1205 CC genotype, signifying unfavorable prognosis.

Disclosure of Interest: None declared

DOI: 10.1136/annrheumdis-2017-eular.2676

\section{FRI0404 THE EFFECT OF A HOME-BASED OROFACIAL EXERCISE PROGRAM ON ORAL APERTURE OF SYSTEMIC SCLEROSIS PATIENTS}

N. Cuzdan Coskun ${ }^{1}$, I. Turk ${ }^{2}$, V. Ciftci ${ }^{3}$, D. Aslan Tas ${ }^{2}$, M.C. Dogan ${ }^{3}$, I. Unal ${ }^{4}$ ${ }^{1}$ Department of Physical Therapy and Rehabilitation, Division of Rheumatology: ${ }^{2}$ Department of Internal Medicine, Division of Rheumatology, Cukurova University Faculty of Medicine; ${ }^{3}$ Department of Pediatric Dentistry, Cukurova University Faculty of Dentistry; ${ }^{4}$ Department of Biostatistics, Cukurova University Faculty of Medicine, Adana, Turkey

Background: Microstomia is one of the major problems that causes multiple dysfunctions and affects quality of life in systemic sclerosis (SSc). ${ }^{1}$

Objectives: The purpose of this study is to evaluate the effect of a home-based orofacial exercise program on the oral aperture $(\mathrm{OA})$ of SSc patients.

Methods: SSc patients who fulfilled the American College of Rheumatology (ACR) 2013 criteria with an OA of $<40 \mathrm{~mm}$ were included in the study. Patients were randomly divided into two groups. Group 1 was given oral augmentation and mouth stretching exercises with combination of strengthening exercise to masseter muscle twice a day for one month in addition to oral hygiene care advices; followed by no activity but oral hygiene care for the next four weeks. Group 2 received oral hygiene care advices for the first one month followed by the same orofacial exercise program twice a day for the next four weeks. Patients' $\mathrm{OA}$ was measured by a dentist at baseline, 1-month, and 2-months.

Results: A total of 52 patients were included in the study. Twenty-seven patients were assigned to group 1 (mean age $53.70 \pm 9.79$ years; $96.3 \%$ female) and twenty-five patients to group 2 (mean age $50.68 \pm 11.93$ years; $96.0 \%$ female). A total of 28 patients (group 1, $n=18$; group 2, $n=10$ ) completed the study. After four weeks period, $O A$ increased in group $1(P<0.001)$, whereas no change was observed in group $2(P=0.906)$. At the end of 2 months the intragroup analysis showed no additional increase in group $1(P=0.283)$, but a statistically significant increase in group 2, regarding the measurement of $O A(P=0.010)$. We didn't find any statistically significant difference between $O A$ measurements of the groups 1 and 2 at the end of the trial $(P=0.830)$.

Conclusions: The results of this pilot study suggested that an intervention of combined home-based orofacial exercise program might improve oral aperture of SSc patients. Future studies with longer follow-up period and higher number of patients are needed to observe the long-term benefits of the presented home-based exercise program.

References:

[1] Frantz C, Avouac J, Distler O, Amrouche F, Godard D, Kennedy AT, Connolly $\mathrm{K}$, Varga J, Matucci-Cerinic M, Allanore Y. Impaired quality of life in systemic sclerosis and patient perception of the disease: A large international survey. Semin Arthritis Rheum. 2016 Aug;46(1):115-23.

Disclosure of Interest: None declared

DOI: 10.1136/annrheumdis-2017-eular.6274

\section{FRI0405 PREVALENCE, CLINICAL CORRELATES AND POSSIBLE CAUSES OF NEUROPATHIC PAIN IN PATIENTS WITH SYSTEMIC SCLEROSIS}

P. Ostojic ${ }^{1}$, S. Knezevic-Apostolski ${ }^{2}$, N. Djurovic ${ }^{3}$, B. Stojic ${ }^{3}$, D. Bartolovic ${ }^{4}$ K. Jankovic ${ }^{5}{ }^{1}$ Institute of Rheumatology, School of Medicine, University of Belgrade; ${ }^{2}$ Neurological Outpatient Clinic "Apostolski"; ${ }^{3}$ Institute of Rheumatology; ${ }^{4}$ Clinic for Medical Biochemistry, Clinical Center of Serbia: ${ }^{5}$ School of Medicine, University of Belgrade, Belgrade, Serbia

Objectives: To assess prevalence, possible causes and clinical correlates of neuropathic pain (NP) in patients with systemic sclerosis (SSc).

Methods: In 42 patients with SSc, presence of NP was assessed using the PainDetect questionnaire and subsequently confirmed by neurological evaluation. Patients with previously diagnosed neurological disorders and diabetes were excluded. Relationship between NP and disease status, symptoms of depression and quality of life was estimated. Index of disease status (IDS) was assessed using the Scleroderma Assessment Questionnaire (SAQ), occurrence of depressive symptoms by the Beck's Depression Inventory (BDI), whilst quality of life was evaluated using the EQ-5D index. In order to evaluate possible causes of NP in SSc, all patients with NP, except one (who did not agree with further assessments) underwent detailed neurological and electroneurography (ENG) examination, as well as $\mathrm{HgbA}_{1} \mathrm{C}$ and vitamin $\mathrm{B} 12$ level testing.

Results: $12 / 42(28.6 \%)$ of patients were found to have NP. Patients with and without NP were similar in age and disease duration. NP was found more frequently in patients with IcSSc $(32.3 \%)$, than in dcSSc $(18.2 \%)$, as well as in patients with ACA (46.7\%) compared to patients with ATA (17.6\%) and both ACA and ATA negative patients (20\%), but the differences were not statistically significant. Patients with NP had significantly higher mean values of IDS (1.28 vs $0.66)$ and $B D I(18.3$ vs 9.9) than patients without NP $(p<0.01)$. Mean value of the $E Q-5 D$ index was significantly lower in patients with NP (0.39 vs $0.79, p<0.01)$. Patients with NP had significantly higher mean value of Index of vascular status, then patients without NP (2.26 vs $1.36, p=0.02)$. $\mathrm{HgbA}_{1} \mathrm{C}$ and vitamin $\mathrm{B} 12$ levels were normal in all SSc patients with NP. Clinical signs of polyneuropathy were noticed in 10 patients by neurological evaluation. Typical symmetric glove-andstocking hyperesthesia was found in 10/11 (90.9\%) of SSc patients with NP, along with symmetric hyporeflexia in 6/11 (54.5\%) patients on lower, and 7/11 (63.6\%) 
on upper extremities. None of patients had allodynia, but impaired vibratory sensibility was found in all patients with NP. Clinical signs of radiculopathy were present in 6 patients. Hypoesthesia was registered in typical dermatomes in $6 / 11$ $(54.5 \%)$ of patients, with asymmetric hyporeflexia in $2 / 11(18.1 \%)$ patients on lower, and none of patients on upper extremities. Despite the fact that almost every patient had symptoms and signs suggesting polyneuropathy, in only four of them demyelinating polyneuropathy was detected by ENG.

Conclusions: NP is common in patients with SSc. Presence of NP is associated with more severe SSc, symptoms of depression and worse quality of life. Almost all SSc patients $(90.9 \%)$ with NP have typical symptoms and signs for polyneuropathy. However, in only few of them polyneuropathy could be detected by ENG. This finding suggests that pure small-fiber polyneuropathy, which is not detectable by ENG, may be the cause of NP in most of patients.

Disclosure of Interest: None declared

DOI: 10.1136/annrheumdis-2017-eular.4492

\section{FRI0406 MORTALITY PROFILE IN SYSTEMIC SCLEROSIS: A LARGE} RETROSPECTIVE POPULATION-BASED STUDY FROM BRAZIL

R.P. Rezende ${ }^{1}$, R. Gismondi ${ }^{1}$, H. Maleh ${ }^{1}$, M.L. Rosa ${ }^{2}$, R. Ramos ${ }^{1}$, L.O. Mocarzel ${ }^{1}$. ${ }^{1}$ Clinical Medicine; ${ }^{2}$ Epidemiology and biostatistics, Universidade Federal Fluminense, Niterói-RJ, Brazil

Background: Systemic sclerosis (SSc) is an uncommon autoimmune multisystem disease associated with reduced life expectancy compared with the general population. ${ }^{1}$ In order to prolong survival of this patient population, clear information on the most important death-related conditions is undoubtedly necessary. No mortality data in SSc, however, are available from Latin America, as well as few large series studies have looked at the mortality profile in SSc.

Objectives: We aimed to describe the causes of death in SSc occurred in the state of Rio de Janeiro, Brazil, from 2006-2015, and also to compare the data gathered with the general population mortality.

Methods: All death certificates issued in the state of Rio de Janeiro, Brazil, from 2006-2015 were screened for the code attributed to SSc according to the tenth revision of the International Classification of Diseases (ICD-10), either as an underlying (UD) cause of death (also referred to as basic cause of death) or a non-underlying (non-UD) cause. In addition to compiling the causes of death in both settings, we calculated the non-adjusted as well as the age bracket-adjusted (age at death $<50$ years and $\geq 50$ years) mortality ratio against the general population for each cause of death when SSc was listed as a non-UD cause.

Results: Of 1.294.491 fatalities recorded over the study period, ICD-10 code for SSc was listed on $374(0.02 \%)$ death certificates, being a basic cause of death on 223 occasions and a non-UD cause on 151 occasions. The overall mean (SD) age at death in SSc was 58.7 (15.6) years, with men $(n=56)$ having an earlier mean age at death than women $(n=318)$ [53.5 vs 59.6 years, respectively; $p=0.004$ ]. For SSc as a basic cause of death, the main non-UD causes were respiratory system diseases $(61.4 \%)$, in particular pneumonia, followed by septicemia (37.6\%), diseases of the circulatory system $(34.9 \%)$, and renal failure $(9.4 \%)$. There were no significant differences between the genders for each cause of death. The mean age at death was significantly lower among men vs women for diseases of the respiratory system, respiratory failure, certain infectious and parasitic diseases, and septicemia. For SSc as a non-UD cause of death, the major conditions leading to death were circulatory system diseases (39\%), in particular pulmonary arterial hypertension (PAH; $13.2 \%)$, followed by certain infections and parasitic diseases $(11.9 \%)$, malignant neoplasms $(10.5 \%)$ and diseases of the digestive system (9.9\%). Compared with the overall population, patients with SSc had an excess of death (odds ratio [OR] $>1$ ) due to PAH (OR 138.94), septicemia (OR 1.92), gastrointestinal hemorrhage (OR 2.40), other systemic connective tissue diseases (OR 24.78) and pulmonary fibrosis (OR 11.05), as well as due to heart failure (OR 6.40) for deaths occurred before age 50 .

Conclusions: We have shown large data on the mortality profile of patients with SSc, the first from Latin America. Of note, infections and cardiorespiratory diseases had a strong impact on mortality, as evidenced by previous publications. ${ }^{1}$ Taking all into account, these data support an increased vigilance for infections, as well as the need to implement effective measures to control modifiable cardiovascular risk factors, including screening for $\mathrm{PAH}$.

References:

[1] Rubio-Rivas M, et al. Semin Arthritis Rheum 2014; 44:208-219.

Disclosure of Interest: None declared

DOI: 10.1136/annrheumdis-2017-eular.5366

\section{FRI0407 MACROVASCULAR INVOLVEMENT IN SYSTEMIC SCLEROSIS PATIENTS: IS THERE A RELATIONSHIP WITH MICROVASCULAR PERIPHERAL BLOOD FLOW?}

S. Paolino ${ }^{1}$, B.M. Colombo ${ }^{2}$, B. Ruaro ${ }^{1}$, E. Gotelli ${ }^{1}$, A. Sulli ${ }^{1}$, M. Ghio ${ }^{1}$, C. Pizzorni ${ }^{1}$, E. Alessandri ${ }^{1}$, M. Patanè ${ }^{1}$, M. Cutolo ${ }^{1}$. ${ }^{1}$ Department of Internal Medicine, University of Genova, IRCCS AOU San Martino, Genoa, Italy, Research Laboratory and Academic Division of Clinical Rheumatology; ${ }^{2}$ IRCCS AOU San Martino, Genoa, Italy, Genoa, Italy

Background: Raynaud's phenomenon and digital ulcers are common clinical skin manifestations of the microvascular dysfunction in systemic sclerosis (SSc).
Although microvascular and macrovascular abnormalities frequently coexist in disease such as diabetes mellitus and other vascular diseases, the possible association between microvascular failure and macrovasculopathy in SSc patients has not been deeply investigated (1).

Objectives: The aim of the study was to estimate in SSc patients the macrovascular function by measuring of the Intima-Media Thickness (IMT) of high-caliber and periferic small-caliber arteries, and to evaluate the possible correlation with microvascular blood perfusion (BP) assessed by Laser Speckle Contrast Analysis (LASCA).

Methods: Twenty-nine female SSc patients (mean age $65.7 \pm 12.07$ SD years, mean disease duration 97.3 $\pm 68.01 \mathrm{SD}$ months) were enrolled after informed consent. Carotid IMT was evaluated through B-mode US imaging (Esaote, Genoa) using transducer $18 \mathrm{MHz}$ on both right and left common carotid arteries (CCA) as well as ulnar (UA) and radial arteries (RadA). Therefore, an average IMT score was obtained for any evaluated site. Peripheral BP was assessed by LASCA (Perimed-Sweden) at the level of fingertips, periungueal areas, dorsum and palm of both hands, and face. The BP values were reported as perfusion units (PU) (2). In addition nailfold videocapillaroscopy (NVC) in order to assess the microvascular morphological status was done by nailfold video capillaroscopy (NVC) considering the different progressive SSc patterns and the microangiopathy evolution score (MES) (3-4).

Results: A positive correlation was observed between CCA IMT and age $(p=0.004)$ and disease duration $(p=0.02)$. On the other hand, no significant correlations were observed between IMT of periferic small-caliber arteries (UA and $\operatorname{RadA}$ ) and age or disease duration. Positive correlations were found between microvascular damage, as assessed by MES and IMT at the level of periferic smallcaliber arteries. No significant correlation was observed between macrovascular involvement of high-caliber arteries and peripheral BP as assessed by LASCA. However, at the peripheral site a correlation was observed between RadA IMT and palm $(p=0.05)$, periungueal $(p=0.04)$ and dorsum of hand $\operatorname{BP}(p=0.0006)$, as assessed by LASCA. UA IMT showed a correlation limited to the dorsum of the hand $(\mathrm{p}=0.003)$.

Conclusions: Significant correlations seem to exist between increased IMT of periferic small-caliber arteries (macrocirculation) and altered peripheral BP (LASCA) at the level of hand microvessels (microcirculation) in SSc patients. These results were found strength by a further correlation with the microvascular damage (MES).

\section{References:}

[1] Hettema Me et al. Rheumatology (Oxford) 2008;47:578-83.

[2] Ruaro B et al. Ann Rheum Dis 2014;73:1181-5.

[3] Sulli A, et al. Ann Rheum Dis 2008:67:885-7.

[4] Cutolo et al. J Rheumatol 2000; 27;155.60.

Disclosure of Interest: None declared

DOI: 10.1136/annrheumdis-2017-eular.6523

\section{FRI0408 NEOPTERIN AS A SEROLOGICAL MARKER OF DISEASE ACTIVITY IN PATIENTS WITH ANTI-MELANOMA DIFFERENTIATION-ASSOCIATED GENE 5 ANTIBODY POSITIVE CLINICALLY AMYOPATHIC DERMATOMYOSITIS}

S. Tsunoda, A. Nishioka, T. Abe, M. Kitano, K. Matsui, H. Sano. Division of Rheumatology, Department of Internal Medicine, Hyogo College of Medicine, Nishinomiya, Japan

Background: Anti-melanoma differentiation-associated gene 5 (MDA5) antibody in clinically amyopathic dermatomyositis (CADM) is associated with rapidly progressive interstitial lung disease (RPILD). RPILD is a rare disorder with a bad outcome, and therefore the intensive treatment with combinational immunosuppressive drugs in addition to steroid need to be initiated. However until now, good serological markers to evaluate disease activity in CADM have not been established. Activated alveolar macrophage is one of the possible candidates worsening the condition of RPILD.

Objectives: To investigate new serological markers of disease activity in antiMDA5 antibody positive CADM for therapeutic indication.

Methods: Thirteen anti-MDA5 antibody positive CADM patients were enrolled. We serially measured serum anti-MDA5 antibody, and neopterin and IL-18 as markers of activated macrophage by serum enzyme-linked immunosorbent assay. We tracked them at three points in each patients: before treatment, soon after a series of intravenous cyclophosphamide pulse therapy (about 3months later after onset) and the remission status (about one year later after onset).

Results: Four patients died soon after the initial treatment because of the deterioration of RPILD. At onset of the disease, the levels of serum anti-MDA5 antibody and neopterin were extremely high (169.75 \pm 24.3 index and $27.6 \pm 24.1$ $\mathrm{nmol} / \mathrm{l})$ in all patients. However serum IL-18 level was almost normal (479.3 \pm 301.4 $\mathrm{pg} / \mathrm{ml}$ ). Among the 9 surviving patients, it took about one year for anti-MDA5 antibody level to decrease to the normal range. On the other hand, neopterin level decreased quickly after the initial treatment. The level of anti-MDA5 antibody transitioned from $169.75 \pm 24.3$ index to $93.1 \pm 50.1$ index, and then to $44.8 \pm 45.4$ index $(P=0.003)$. Neopterin level transitioned from $27.6 \pm 24.1 \mathrm{nmol} / \mathrm{l}$ to $9.1 \pm 6.5 \mathrm{nmol} / \mathrm{l}$, and then to $6.4 \pm 5.0 \mathrm{nmol} / \mathrm{l}(\mathrm{P}=0.006)$. IL-18 level transitioned from $479.3 \pm 301.4 \mathrm{pg} / \mathrm{ml}$ to $246.0 \pm 175.8 \mathrm{pg} / \mathrm{ml}$, and then to $233.3 \pm 180.1 \mathrm{pg} / \mathrm{ml}$ $(P=0.02)$. The level of anti-MDA5 didn't correlate with the level of ferritin $(r=0.28)$, neopterin $(r=0.16)$, IL-18 $(r=0.06)$ and soluble IL-2 receptor $(r=0.27)$, but the level 